Check for updates

Cite this: RSC Adv., 2018, 8, 39691

Received 15th October 2018

Accepted 16th November 2018

DOI: $10.1039 / \mathrm{c} 8 \mathrm{ra0} 8540 \mathrm{~d}$

rsc.li/rsc-advances

\section{Control of the stereochemistry of C14 hydroxyl during the total synthesis of withanolide $E$ and physachenolide $\mathrm{C} \uparrow$}

\author{
M. Anees, (D) a S. Nayak, (D) b K. Afarinkia (iD *a and V. Vinader (D) *a
}

The stereochemical outcome of the epoxidation of $\Delta_{14-15}$ cholestanes with mCPBA is controlled by the steric bulk of a $\mathrm{C} 17$ substituent. When the $\mathrm{C} 17$ is in the $\beta$ configuration, the epoxide is formed in the $\alpha$ face, whereas if the C17 is trigonal (flat) or the substituent is in the $\alpha$ configuration, the epoxide is formed in the $\beta$ face. The presence of a hydroxyl substituent at C20 does not influence the stereochemical outcome of the epoxidation.

\section{Introduction}

Recently, two ergostane natural products, physachenolide $\mathbf{C ,}, \mathbf{1 , 2} \mathbf{1}$ and withanolide $\mathrm{E},{ }^{3-8} 2$ (Fig. 1) have attracted considerable attention because of their interesting and unusual anti-tumour properties. Key structural features of both molecules include the C14 $\alpha$-hydroxylation (which is relatively less common compared to $\mathrm{C} 14 \beta$-hydroxylation in steroids) as well as $\mathrm{C} 17 \beta$ and pro-R hydroxylation at $\mathrm{C} 20$. Neither compound has been totally synthesised previously. So far, through semi-synthesis and derivatisation of authentic samples, a limited amount of information about their structure activity relationships has been gathered. None of these studies however have established the role of the three tertiary hydroxyl groups at $\mathrm{C} 14 \alpha, \mathrm{C} 17 \beta$ and C20 in the potency of the molecules. Clearly a total synthesis approach to physachenolide C, $\mathbf{1}$ and its deoxy analogues, which include withanolide E, 2, will allow us to explore the contribution that these various hydroxyl groups make to the biological activity of these molecules.

Therefore, we have recently set out on a total synthesis of physachenolide C, $\mathbf{1}$ and withanolide E, 2. As part of this total synthesis, we envisaged a route consisting of sequential introduction of C-14 $\alpha$ hydroxyl, followed by functionalisation of angular C18 methyl group, mediated by the C-20 hydroxyl; ${ }^{9-11}$ which will lead to a total synthesis of physachenolide C, 1 (Fig. 1). If this step is omitted, the follow on steps, introduction of $\mathrm{C}-17 \beta$ hydroxyl and chain extension at C-20, will lead to

${ }^{a}$ Institute of Cancer Therapeutics, University of Bradford, Bradford BD7 1DP, UK E-mail: m.vinader@bradford.ac.uk

${ }^{b}$ School of Chemistry \& Biosciences, University of Bradford, Bradford BD7 1DP, UK $\dagger$ Electronic supplementary information (ESI) available: For detailed experimental procedure and characterisation of all compounds. CCDC 1861117. For ESI and crystallographic data in CIF or other electronic format see DOI: 10.1039/c8ra08540d withanolide E, 2. Here we describe our approach to the stereoselective introduction of the $\mathrm{C} 14 \alpha$ hydroxyl group.

A number of strategies for the stereoselective introduction of a hydroxyl group at the C14 position of steroids have been described; however they mainly lead to the $\beta-\mathrm{OH}$ configuration. These include hydrobromination of $\Delta_{14-15}$ steroid followed by removal of bromine from C-15; ${ }^{\mathbf{1 2 - 1 5}}$ Norish type II reaction of C12 ketosteroids, ${ }^{16}$ metal catalysed hydration of $\Delta_{14-15}$ steroid, ${ }^{17}$ metal $^{18,19}$ or enzyme catalysed direct conversion of $\mathrm{C} 14-\mathrm{H}$ to $\mathrm{C} 14-\mathrm{OH},{ }^{20-22}$ and through tandem construction of steroid's ring D. ${ }^{23}$

In our synthetic path, we opted for selective introduction of C-14 $\alpha$ hydroxylation via epoxidation of $\Delta_{14-15}$, followed by regioselective reduction at $\mathrm{C} 15$ to generate the corresponding alcohol (Fig. 1). A survey of the literature reveals only three related examples, one of them being compound $\mathbf{3}$, where the
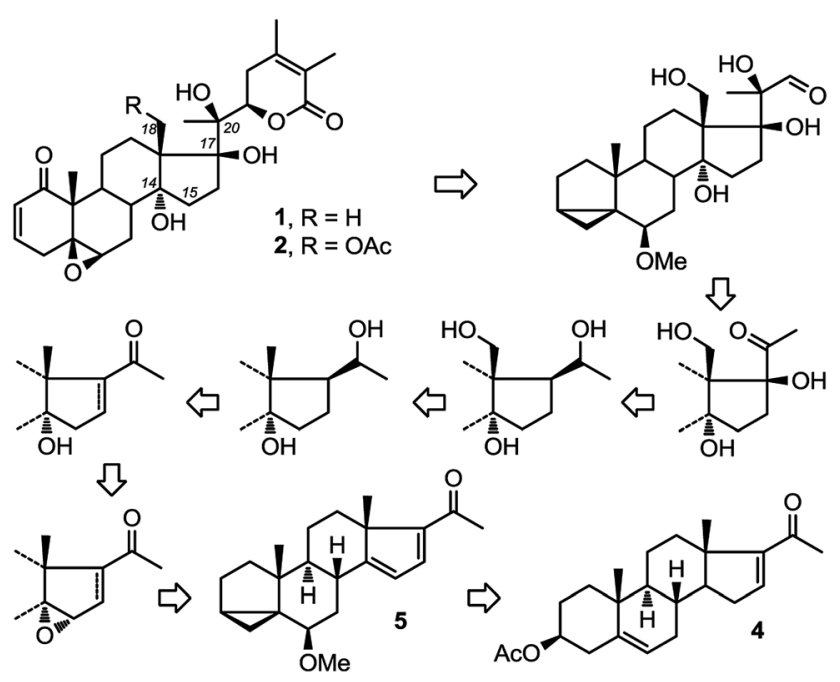

Fig. 1 A route to withanolide E, 1 and physachenolide $C, 2$. 

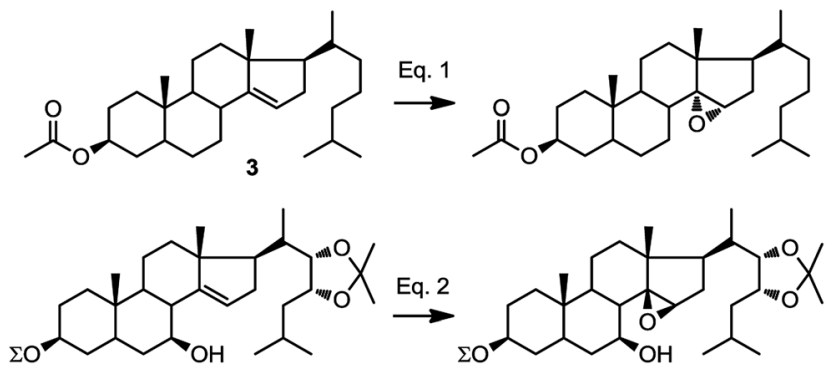

$\Sigma=$ tert $-\mathrm{BuPh}_{2} \mathrm{Si}$

Fig. 2 Diastereofacial selectivity in the epoxidation of C14-C15.25,29

stereochemical outcome of the epoxidation was assigned as $\alpha$ (Fig. 2, eqn (1)). ${ }^{24-27}$ However, a rationale for the stereoselectivity was not provided in any of these examples. In contrast, direct epoxidation from the $\beta$ face is reported only in two cases, where an adjacent (homo-allylic) hydroxyl group can direct the stereoselective introduction of oxygen, presumably through hydrogen bonding to the reagent, mCPBA (Fig. 2, eqn (2)). ${ }^{28,29}$

Based on this information, we were confident that installation of the C-14 hydroxyl can be achieved from the $\alpha$ face, however, we discovered steric factors affecting the stereoselectivity of that epoxidation which we describe below.

\section{Results and discussion}

Starting from commercially available 4, we first set out to prepare 5 (Fig. 3). Molecule 5 contains two alkene groups, and our expectation was that only the C14-C15 double bond (and not the C16-C17 double bond) will undergo epoxidation, as it is
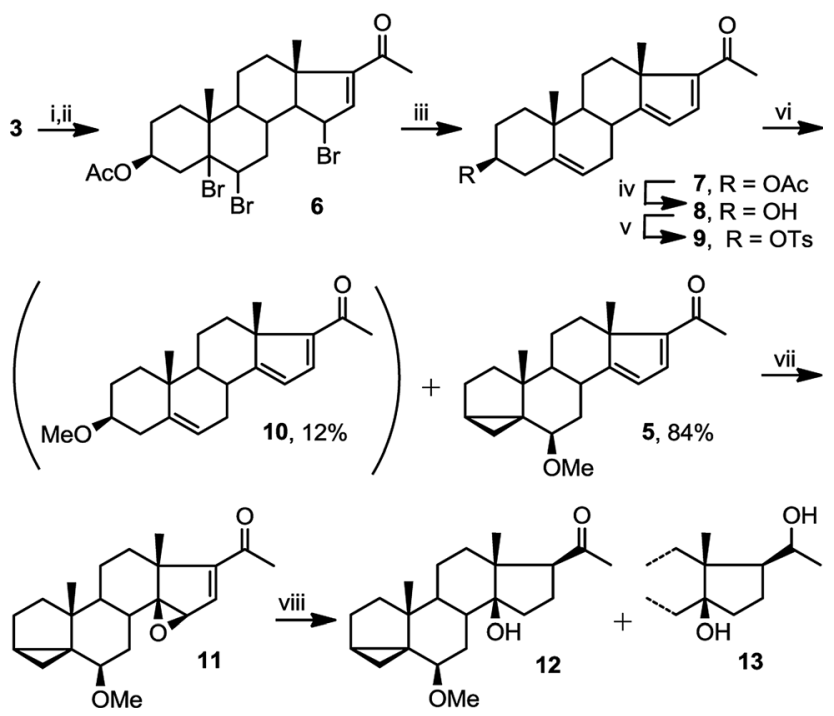

Fig. 3 Preparation of epoxide 11 and its reduction to 12. (i) $\mathrm{KOAc}, \mathrm{Br}_{2}$ (acetic acid), ether, $0{ }^{\circ} \mathrm{C}$; (ii) NBS, AIBN, EtOAc, reflux; (iii) Nal, reflux (39\% over 3 steps); (iv) $\mathrm{KOH}, t$-butanol, $30{ }^{\circ} \mathrm{C}, 10 \mathrm{~h}(100 \%)$; (v) $\mathrm{TsCl}$, pyridine, 28 h (83\%); (vi) $\mathrm{MeOH}$, pyridine (3 eq), reflux (84\%); (vii) mCPBA (81\%); (viii) $\mathrm{LiAlH}_{4}$, THF, reflux 2 h (12, 42\%; 13, 23\%). further away from the electron withdrawing carbonyl group. Molecule 5 also contains a 6-methoxy-3,5-cyclochole-stane as a masked $3 \beta$-hydroxycholest-5,6-ene (see below). ${ }^{30,31}$

Treatment of 3 with bromine, in order to temporarily mask the $\mathrm{C} 5-\mathrm{C} 6$ alkene, followed by the bromination of the only remaining allylic position next to the $\mathrm{C} 16-\mathrm{C} 17$ double bond afforded 6, which upon debromination yielded 7. Hydrolysis of the $3 \beta$-OAc to alcohol 8 and subsequent conversion of the alcohol to a tosylate afforded 9. Treatment of tosylate 9 with methanol in the presence of mild base (pyridine) mainly results in homo-allylic displacement of the tosylate to afford 5 . The reaction also produced $\mathbf{1 0}(11 \%)$ as a by-product, resulting from double substitution with methanol acting as nucleophile and attacking $\mathbf{5}$ at C3. This sequence of reactions effectively masks and protects the $\mathrm{C} 5-\mathrm{C} 6$ double bond. There is sufficient precedence in the literature to suggest that unmasking of the group can be accompanied by introduction of $\mathrm{C} 2-\mathrm{C} 3$ alkene and derivatisation of the ring $\mathrm{A}$ which is required in the total synthesis of physachenolide C. ${ }^{8,32-34}$

Treatment of 5 with mCPBA afforded a single epoxide, 11, and treatment of $\mathbf{1 1}$ with limiting amount of $\mathrm{LiAlH}_{4}$ yielded alcohol, $\mathbf{1 2}$ as well as fully reduced product, compound $\mathbf{1 3}$. Analysis of the configuration of C14 hydroxyl in 12, using a previously established method based on NMR chemical shifts was inconclusive at that time (see below). However, X-ray crystallography confirmed the configuration of $\mathbf{1 1}$ to be the undesired $\beta$ configuration. ${ }^{35}$ We concluded therefore, that the C14 hydroxyl in 12 also had a $\beta$ configuration (Fig. 4 and 5).

This epoxidation from the $\beta$ face in $\mathbf{5}$ is in contrast to the available literature precedence, showing epoxidation occurs from the $\alpha$ face in 4 (Fig. 2) ${ }^{25}$ Of course, the difference between 5 and 4 is that in the latter, the C17 substituent is at the $\beta$ configuration. Therefore, we presumed that $\mathrm{C} 17$ substituent may provide steric hindrance in the $\beta$ face, driving the introduction of epoxides from the $\alpha$ face. To confirm our hypothesis, we set out to prepare $\mathbf{1 4}$ and to determine whether the configuration of its epoxidation would differ that of $\mathbf{5}$. Regioselective reduction of $\mathrm{C} 16-\mathrm{C} 17$ double bond in 5 afforded a mixture of two C-17 epimers, compounds 14 with $\beta$ configuration at C-17, and 15 with $\alpha$ configuration at $\mathrm{C}-17$. This was in contrast to a previous report that indicated that a similar reduction was stereoselective. ${ }^{36}$ Unfortunately, the two isomers, $\mathbf{1 4}$ and $\mathbf{1 5}$,

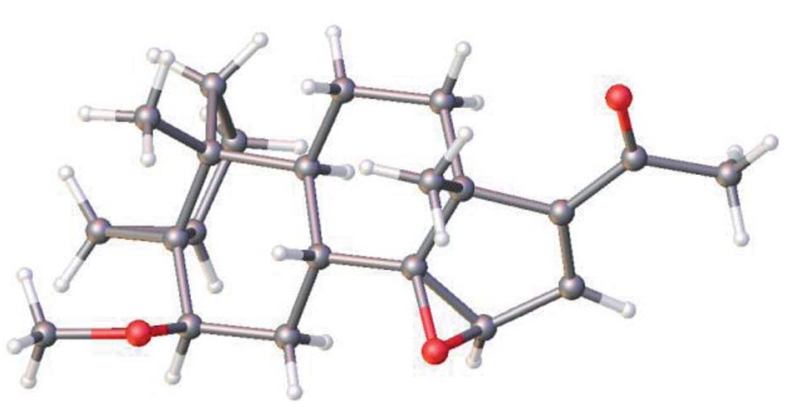

Fig. 4 Molecular structure of 11 as determined by single crystal X-ray diffraction showing the configuration of epoxide. Colour code for the atoms: $\mathrm{C}$ (grey), $\mathrm{H}$ (white), and $\mathrm{O}$ (red). 

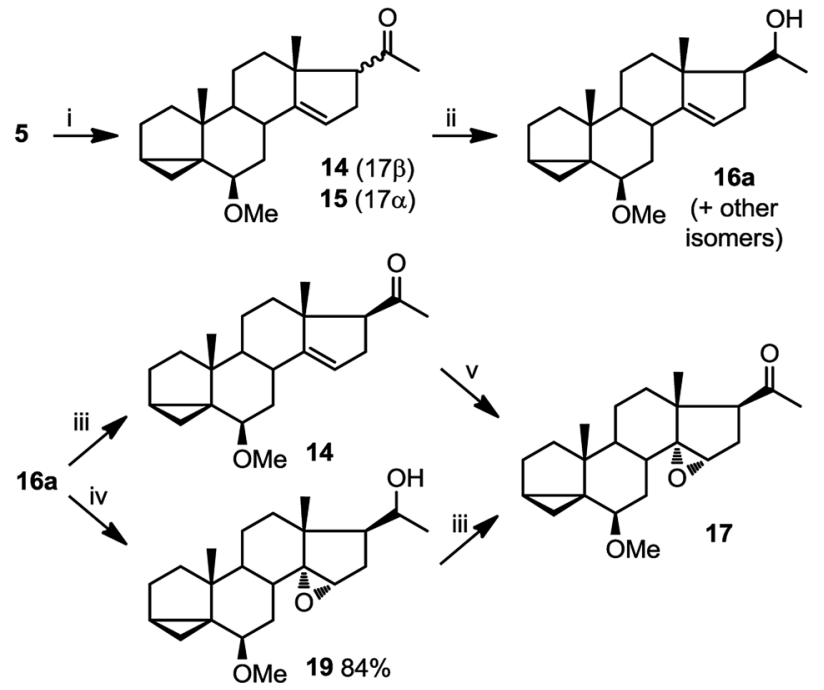

Fig. 5 Preparation of epoxide 17. (i) $\mathrm{Ph}_{3} \mathrm{SnH}, \mathrm{AIBN}$, toluene, reflux, $10 \mathrm{~h}$ (39\%); (ii) $\mathrm{NaBH}_{4}, \mathrm{MeOH} / \mathrm{CH}_{2} \mathrm{Cl}_{2}, 40$ min (58\% for 16 aplus $32 \%$ combined yield of other isomers); (iii) $\mathrm{PDC}, \mathrm{CH}_{2} \mathrm{Cl}_{2}, 48 \mathrm{~h}(78 \%$ ); (iv) mCPBA, $\mathrm{CHCl}_{3}, 3 \mathrm{~h}(84 \%)$; (v) mCPBA, $\mathrm{CHCl}_{3}, 3 \mathrm{~h}$ (93\%).

were not separable in our hands. This isomeric mixture was reduced with $\mathrm{NaBH}_{4}$, affording a mixture of the four possible stereoisomers. The major isomer, 16a was isolated by chromatography and then converted back to 14 by treatment with PDC. Treatment of 14 with mCPBA afforded 17, in which the epoxide was later shown to have $\alpha$ configuration (vide infra).

The observed $\alpha$ configuration of the epoxide in the oxidation of $\mathbf{1 4}$ is in contrast to the observed $\beta$ configuration of the epoxide in the oxidation of $\mathbf{5}$. This is presumably due to the differing configuration between the substituents at C17. In compound 14, C17 substituent is in $\beta$ (up) configuration whereas in 5, C17 substituent is flat. We next set out to show that commensurate to this observation, epoxidation of $\mathbf{1 5}$, where the $\mathrm{C} 17$ substituent is in $\alpha$ (down) configuration affords an epoxide with $\beta$ (up) configuration.

We were unable to obtain a sample of 15 which was completely free from 14. However, when epoxidising a mixture of 15 and 14, we obtained only two products: one of which is $\mathbf{1 7}$ as expected (from epoxidation of 14). The other, 18, was assigned with a $\beta$ epoxide configuration (Fig. 6) (vide infra).

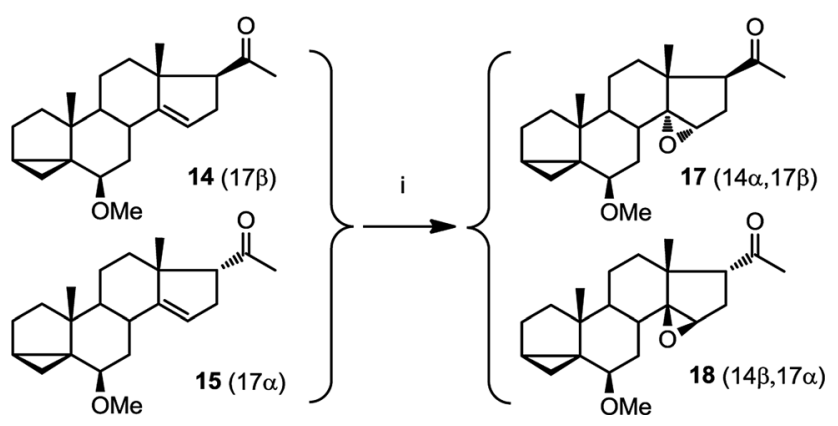

Fig. 6 Epoxidation of a mixture of 14 and 15 to 17 and 18. (i) mCPBA, $\mathrm{CHCl}_{3}, 3 \mathrm{~h}(93 \%)$.
In oxidations with mCPBA, steric encumbrance can sometimes be overcomed by directing the delivery of the oxygen atom through hydrogen bonding of the reagent to an adjacent hydroxyl group. This has been shown in the literature as we have previously indicated (Fig. 2, eqn (2)). ${ }^{29}$ To investigate this, we carried out an epoxidation of $\mathbf{1 6 a}$, which contains a hydroxyl group at C20, with mCPBA. The reaction afforded an epoxide 19 which after treatment with PDC, produced compound 17. This means that surprisingly, a hydroxyl group at C20, regardless of its configuration, is unable to direct the mCPBA epoxidation away from the $\alpha$ face.

The assignment of C14 $\beta$ hydroxyl configuration in compound 12 was deduced from compound 11, where X-ray crystallography had confirmed presence of a $\beta$ epoxide. To unequivocally assign the configuration of epoxides 17-19 and their corresponding alcohols (see above) we used NMR chemical shifts.

A key feature in the NMR spectra that supports the assignment of the epoxide configuration is the value of the chemical shift for C18 protons. In both 17 and 19 (where the configuration of the C14-C15 epoxide is $\alpha$ ) and in 14 (where there is no epoxide at $\mathrm{C} 14-\mathrm{C} 15)$, the chemical shift for protons on $\mathrm{C} 18$ are similar and at $0.81,1.01$ and $0.89 \mathrm{ppm}$ respectively. However, in compound $\mathbf{1 1}$ and $\mathbf{1 8}$ (where the configuration of epoxide is $\beta$ ) the $\mathrm{C} 18$ protons are subject to magnetic anisotropy effect by the oxygen atom in the epoxide and therefore, their chemical shift is increased to 1.28 and $1.32 \mathrm{ppm}$ respectively. These variations in the chemical shifts of C18 protons are consistent with those previously reported in similar structures. ${ }^{37}$

Another way in which NMR can be used to confirm the configuration of epoxides is by assessing the $\gamma$ gauche effect in the molecules. It has been previously established that in steroids, a $14 \alpha$ hydroxyl group shields C12 and C17 through $\gamma$ gauche effect more than a $14 \beta$ hydroxyl group does. ${ }^{38-40} \mathrm{C} 17$ is easily identifiable in NMR due to its distinctive chemical shift at around $60 \mathrm{ppm}$. As an example from the literature, in compound 20, containing $\mathrm{C} 14 \alpha$ hydroxylation, the chemical shift of C-17 is 2.8 ppm lower than that for compound 21, containing no $\mathrm{C}-14$ hydroxylation; whereas the difference between the values for 22 containing C14 $\beta$ hydroxylation, and 21 is only $1.6 \mathrm{ppm}$ (Table 1). ${ }^{40}$ The only limitation to this method is that we require a deoxy analogue to measure the differences in chemical shifts.

Therefore, we set out to prepare the corresponding deoxy and $\mathrm{C} 14 \alpha$ analogues for comparison of their C17 chemical shifts. Compound 19 was first converted into 23 by treatment with $\mathrm{LiAlH}_{4}$ and then to $\mathbf{2 4}$ by treatment with PDC (Fig. 7). Compound 25 was obtained as a byproduct from hydrogenation of 11, along with compounds 12 and 26.

The comparison between the chemical shift of $\mathrm{C} 17$ between compounds 20-22 and 24, 25 and 12 is shown below (Table 1). The larger deshielding of $\mathrm{C} 17$ in compound 25 compared to that in compound 24 (4.9 ppm) than 12 (3.5 ppm) supports the assignment of $\mathrm{C} 14 \alpha$ hydroxyl configuration in compound 24 . 
Table 1 Comparison of the $\gamma$ gauche effect on chemical shifts between compounds 20 with 21, 24 with 23 , and 24 with 12

\begin{tabular}{llllll}
\hline & \multicolumn{5}{l}{ Chemical shifts for compounds } \\
\cline { 2 - 6 } Position & $\mathbf{2 0}(\alpha)$ & $\mathbf{2 1}$ & $\mathbf{2 3}(\beta)$ & $\mathbf{2 4}(\alpha)$ & $\mathbf{2 5}$ \\
\hline$\delta \mathrm{C}-17(\mathrm{ppm})$ & $61.1(-2.8)$ & 63.9 & $62.3(-1.6)$ & $60.0(-4.9)$ & 64.9
\end{tabular}
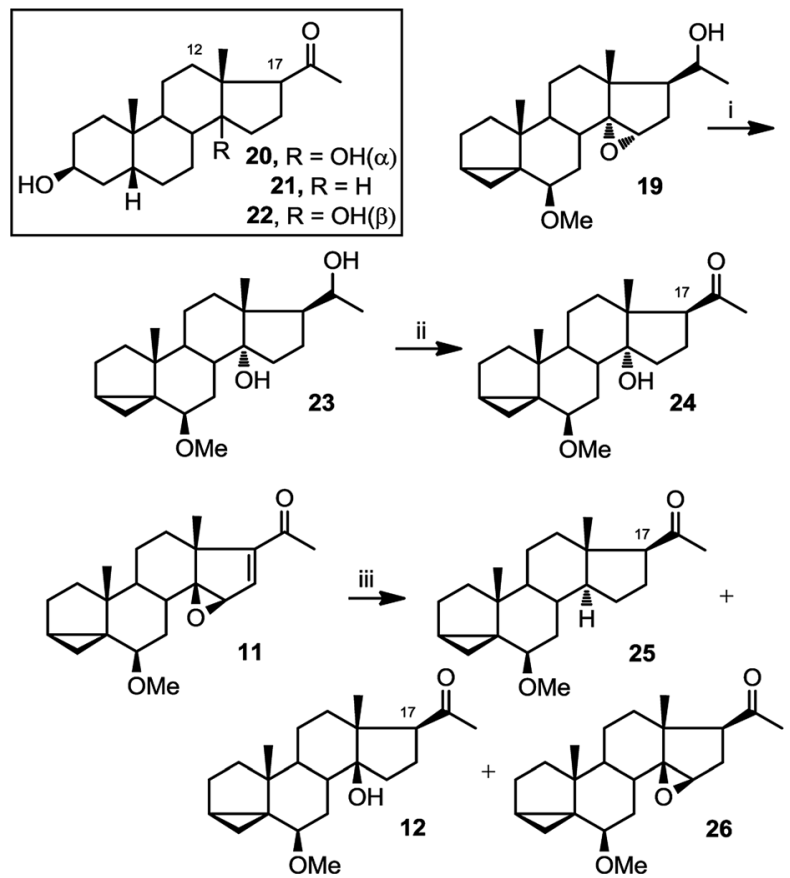

Fig. 7 Preparation of 23-26. (i) $\mathrm{LiAlH}_{4}, \mathrm{THF}$, reflux, overnight (61\%); (ii) PDC, $\mathrm{CH}_{2} \mathrm{Cl}_{2}$, overnight (77\%); (iii) $\mathrm{H}_{2}$ (g), $10 \% \mathrm{Pd} / \mathrm{C}$, methanol, r.t.p., 15 h $(25,17 \% ; 12,37 \% ; 26,34 \%)$.

\section{Conclusions}

In summary, the configuration of the epoxide in the mCPBA oxidation of C14-C15 alkenes function during the total synthesis of physachenolide $\mathrm{C}$ and withanolide $\mathrm{E}$ is determined by the configuration of the $\mathrm{C} 17$ substituent. When the $\mathrm{C} 17$ is in the $\beta$ configuration, the epoxide is formed in the $\alpha$ face, whereas if the $\mathrm{C} 17$ is trigonal (flat) or the substituent is in the $\alpha$ configuration, the epoxide is formed in the $\beta$ face.

\section{Experimental}

Synthetic procedures and full characterisation data are provided in the ESI†.

\section{Conflicts of interest}

There are no conflicts of interest to declare.

\section{Acknowledgements}

We thank University of Bradford for a bursary (MA).

\section{Notes and references}

1 H. Zhang, C. M. Cao, R. J. Gallagher, V. W. Day, K. Kindscher and B. N. Timmermann, Phytochemistry, 2015, 109, 147-153.

2 Y. M. Xu, M. X. Liu, N. Grunow, E. M. Wijeratne, G. PaineMurrieta, S. Felder, R. M. Kris and A. A. Gunatilaka, J. Med. Chem., 2015, 58, 6984-6993.

3 C. J. Henrich, A. D. Brooks, K. L. Erickson, C. L. Thomas, H. R. Bokesch, P. Tewary, C. R. Thompson, R. J. Pompei, K. R. Gustafson, J. B. McMahon and T. Sayers, Cell Death Dis., 2015, 6, e1666.

4 M. C. Gu, Y. K. Yu, G. M. K. B. Gunaherath, A. A. L. Gunatilaka, D. P. Li and D. X. Sun, Invest. New Drugs, 2014, 32, 68-74.

5 I. Prassas, G. S. Karagiannis, I. Batruch, A. Dimitromanolakis, A. Datti and E. P. Diamandis, Mol. Cancer Ther., 2011, 10, 2083-2093.

6 C. Y. Yen, C. C. Chiu, F. R. Chang, J. Y. F. Chen, C. C. Hwang, Y. C. Hseu, H. L. Yang, A. Y. L. Lee, M. T. Tsai, Z. L. Guo, Y. S. Cheng, Y. C. Liu, Y. H. Lan, Y. C. Chang, Y. C. Ko, H. W. Chang and Y. C. Wu, BMC Cancer, 2010, 10, 46.

7 T. Dasdia and A. Dimarco, Eur. J. Cell Biol., 1980, 22, 548.

8 A. Perez-Medrano and P. A. Grieco, J. Am. Chem. Soc., 1991, 113, 1057-1059.

9 P. Tang and B. Yu, Eur. J. Org. Chem., 2009, 259-269.

10 J. M. Sonego, A. M. Cirigliano, G. M. Cabrera, G. Burton and A. S. Veleiro, Steroids, 2013, 78, 644-650.

11 H. Suginome, Y. Nakayama and H. Senboku, J. Chem Soc. Perkin Trans. 1, 1992, 1837-1842.

12 P. Kočovský and I. Stieborová, Tetrahedron Lett., 1989, 30, 4295-4298.

13 U. Stache, W. Fritsch, W. Haede, K. Radscheit and K. Fachinger, Justus Liebigs Ann. Chem., 1969, 726, 136-144. 14 S. Lociuro, T. Y. R. Tsai and K. Wiesner, Tetrahedron, 1988, 44, 35-40.

15 U. K. Pati and K. Wiesner, Heterocycles, 1989, 29, 275-282.

16 P. Geoffroy, B. Ressault, E. Marchioni and M. Miesch, Steroids, 2011, 76, 1166-1175.

17 H. Renata, Q. Zhou and P. S. Baran, Science, 2013, 339, 59-63.

18 Z. Fang and R. Breslow, Org. Lett., 2006, 8, 252-254.

19 M. D. Kaufman, P. A. Grieco and D. W. Bougie, J. Am. Chem. Soc., 1993, 115, 11648-11649.

20 C. S. Bensasson, J. R. Hanson and Y. Le Huerou, Phytochemistry, 1999, 52, 1279-1282.

21 J. Boynton, J. R. Hanson and A. C. Hunter, Phytochemistry, 1997, 45, 951-956.

22 J. R. Hanson, P. B. Hitchcock and A. C. Hunter, Phytochemistry, 1998, 49, 1287-1292. 
23 N. R. Cichowicz, W. Kaplan, Y. Khomutnyk, B. Bhattarai, Z. Sun and P. Nagorny, J. Am. Chem. Soc., 2015, 137, 14341-14348.

24 S. Araki, S. Eguchi and M. Morisaki, Chem. Pharm. Bull., 1990, 38, 1796-1797.

25 M. E. Jung and T. W. Johnson, Tetrahedron, 2001, 57, 14491481.

26 M. S. Bjelakovic, N. M. Krstic, N. Todorovic, A. Krunic, B. Tinant, M. M. Dabovic and V. D. Pavlovic, Tetrahedron, 2009, 65, 9557-9568.

27 A. Lardon and T. Reichstein, Helv. Chim. Acta, 1962, 45, 943962.

28 K. Michalak, M. Morawiak and J. Wicha, Org. Lett., 2016, 18(23), 6148-6151.

29 M. Li, P. Zhou and A. Wu, Tetrahedron Lett., 2006, 47, 34093412.

30 T. Gebreyesus and C. Djerassi, J. Org. Chem., 1985, 50, 154156.

31 H. Suginome and Y. Nakayama, J. Chem. Soc. Perkin Trans. 1, 1992, 1843-1848.
32 T. Kametani, T. Katoh, M. Tsubuki and T. Honda, J. Am. Chem. Soc., 1986, 108, 7055-7060.

33 W. S. Zhou, B. Jiang and X. F. Pan, J. Chem. Soc. Chem. Commun., 1988, 791-793.

34 V. Richmond, G. A. G. Santos, A. P. Murray and M. S. Maier, Steroids, 2011, 76, 1160-1165.

35 The crystal structure and data for compound 11 can be retrieved from Cambridge Crystallographic Data Centre (deposition number 1861117).

36 E. Yoshii, T. Oribe, K. Tumura and T. Koizumi, J. Org. Chem., 1978, 43, 3946-3950.

37 E. Glotter, S. Kumar, M. Sahai, A. Goldman, I. Kirson and M. Mendelovici, J. Chem. Soc. Perkin Trans. 1, 1991, 739-745.

38 E. Glotter, M. Sahai and I. Kirson, J. Chem. Soc. Perkin Trans. 1, 1985, 2241-2245.

39 H. Zhang and B. N. Timmermann, J. Nat. Prod., 2016, 79, 732-742.

40 S. C. Bensasson, R. J. Hanson and L. Y. Huerou, Phytochemistry, 1999, 52, 1279-1282. 